\title{
Human-Wildlife Coexistence In Omay Communal Land, Nyaminyami Rural District Council In Zimbabwe
}

\author{
Leward Jeke \\ Department of Economics, University of Fort Hare, East London Campus, Private Bag X1314, 5700, South Africa. \\ Email: lewardjeke@gmail.com or LJeke@ufh.ac.za
}

\section{Doi:10.5901/mjss.2014.v5n20p809}

\section{Abstract}

The coexistence between humans and wildlife has sparked a fire unquenchable in Omay communal land. Omay communal land is an unprotected area where wildlife and humans have been coexisting before and after the formation of the Nyaminyami District subsequent to the construction of Kariba Dam to date. Human-wildlife conflicts have turn out to be more frequent and severe over recent decades as a consequence of human population growth, extension of transport routes, and expansion of agricultural and industrial activities that have led to increased human encroachment on previously wild and uninhabited areas. In Omay communal land, this has since led to an increased competition for the available natural habitats and resources. Some households experience serious losses whereas other households go unscathed, especially the ones that are far from the borders of wildlife habitats. It is factual that human-wildlife conflicts are inevitable if the two are to share the same land. The conflicts are exacerbated as humans encroach on wildlife corridors and, potentially, as wildlife repopulate human-dominated landscapes of Omay communal land.

Keywords: Human-Wildlife Conflict; Unprotected Area; Nyaminyami Rural District Council; Communities.

\section{Introduction}

Nyaminyami Rural District is one of the least developed districts in Zimbabwe which suffers a dual disadvantage of limited agricultural potential due to poor agro-ecological conditions and the presence of wildlife and animal diseases. Nyaminyami Rural District Council (NRDC) is far from markets and therefore it receives poor supplies of food at high prices, at the same time earning low value from livestock which is sold out of the area (Save the Children, April 2003). NRDC is located in the Zambezi Valley of northern Zimbabwe (Taylor., D. R 1994), and is named for the resident Tonga people's protective ancestral spirit, Nyami Nyami. It is the least developed and poorest of Zimbabwe's 55 rural districts. The district consists of 12 wards and it reached its current configuration in 1960 after the completion of the dam on the Zambezi river at Kariba. The construction of the Kariba dam in the years 1955 to 1959 resulted in the submergence of approximately 5500 square kilometers of terrain which was largely home to various wild animal species. Not only did the wild animals and humans lost their habitat and green pastures for the nurture animals, they also lost rich natural resource base in fertile alluvial soils from Zambezi river tributaries which allowed population densities to build up to levels which were high by Central African standards (Scudder, T., 2005). The dam consumed the vast of the land that was available for both the humans, livestock and wildlife. This has since led to human wildlife conflicts exacerbated currently as the population of local communities has grown and the communities continue cutting down trees for agricultural purposes.

\section{Nyaminyami Rural District Council Communities}

NRDC residents survive by doing agriculture, rearing of livestock and receiving a share of the proceeds from the availability of wildlife via dividends. The land area in Omay communal land falls into natural region five $(\mathrm{V})$ which is the last category with little or no rains (dry spell region suitable for semi-extensive and extensive farming). Despite the fact of the low productivity of the land, the majority of the population in Omay Communal Lands is engaged in farming and nurture of livestock whilst wild-animals devour the crops, livestock and humans. The land in NRDC is very dry as it receives trifling rainfall, which sometimes cannot even support plant life. The climatic conditions are barely good for keeping of livestock or wildlife as the soils are not good enough for crop production due to abysmal terrain and mountainous ranges. The temperatures are always high during summer and winter, the soil quality is so poor and most of the places in NRDC lack perennial water for gardening. The dams that are in Omay Communal Lands dry up before the rain season due to availability of livestock, wildlife and humans collecting water from them. There are no irrigation 
schemes that are being practiced as the available dams cannot hold much water to sustain the growing population of humans, livestock and wildlife.

In any given area, water sources, availability of land, rainfall patterns, the nature of the soils, the temperatures and climates shapes the survival of the species in any given environment. These are the vital determinants of production. The more buoyant these factor of production, the better the potential of doing agriculture and other productive uses of land. Transport services to these rural areas are a big challenge due to the horrific state of the roads, there is poor telecommunications, no markets for few produces that the communities produce. The infrastructural developments are very poor and beyond existence. In Omay communal lands, poverty is ubiquitous due to all the factors.

\section{The Intensity of Human-Wildlife Conflicts in Omay Communal Land, NRDC}

It is so contemptible to find numerous and inexhaustible scholarly in scientific databases and textbooks when you search for the term "human wildlife conflicts". This will just confirm the enormity and atrociousness at which the wildlife and humans are on warpath terms, not in a single country or few countries, but in the whole world. NRDC is one of the places that has been hidden from media and research due to lack of funding research in the country. The human wildlife conflicts in Omay communal lands are acute and people are losing their lives, livestock and food crops. In this paper, the term human wildlife conflict refers to the problems that the communities and residents of NRDC faces due the availability of wildlife in the form of devouring of livestock/humans, agricultural products and other losses that communities face from the wildlife. The two terms "wildlife" or "wild animals" will be used interchangeably in this research thesis referring to all the animals that are not reared or domesticated by humans and cohabit in the forests and are not pets.

There is a lot of research that has been conducted with regards to the coexistence between wildlife and humans. All the research output found that wildlife and humans cannot live in a collegial manner. Wildlife and humans are antagonistic resulting to different methods and proposals being put forward to eliminate or reduce the conflicts. According to Madden, F., (2004), wildlife and humans increasingly compete for space, resources and places to call home. Human wildlife conflict is increasing in both frequency and severity worldwide and is prone to continue to escalate. Both protected and unprotected areas are increasingly becoming islands of habitat surrounded by seas of cultivation and development. For unprotected areas like Omay communal land, the land that has been left for animals includes galleys, swamps and mountainous places where people cannot practice agricultural production. This land is so small for very large mammals like elephants and buffaloes that reside in these areas, not even is the land so small, the area is in region five (v) and receives little or no rainfall that cannot provide a green pasture for both livestock and wildlife.

Nyaminyami Rural District Council's population is growing at the rate of 17\%(34 454 to 41420$)$ and the households growing at the rate of 22\% (7475 to 9565) in a decade between 1992 and 2012. This really shows that the benefits of wildlife have been diluted. As the human population continues to grow, more and more of native wildlife's natural habitat is being demolished and turned into human occupation. As human populations increase, settled agriculture spreads to more marginal rangelands and conflict between wildlife and people increases (Anderson, J., Bakker, L., Lagrange, M., Lamarque, F., Fergusson, R., and Osei-Owusu, F. A. O., 2009). Human encroachment into natural areas has led to increasing conflicts between people and wildlife as they are forced into sharing the same territory. The interactions between people and wild animals causes great physical suffering and/ emotional trauma to both the humans and the animals.

Omay communal land is a rural area where communities solely depend on subsistence farming and livestock production for their day to day lives. Omay is highly endowed with an enormous diversity of ecosystems and wildlife species. It has a diverse assemblage of large mammals like elephants, leopards, buffalos and lions. Owing to limited resources, human and wildlife conflicts has become a big problem. Current efforts to address this issue have met with limited success. In other countries, human wildlife conflicts has been reduced by enacting new regulations or issuing public service announcements that stressed the dangers of close contact with wild animals. Most of these regulations are based on the belief that people could be motivated by fear, the fear of violating the law and the fear that they might be exposing themselves to injury or diseases like rabies. The other options may be to engage government and non-profit agencies in a team effort to provide educational resources that empower the public with the knowledge and skills needed to safely live alongside wildlife, and secondly to actively involve interested citizens in developing innovative ways that can fulfill their desire to interact with wildlife without endangering themselves and the animals.

Some economists and policy makers via for protected areas as a way to protect wildlife and humans from conflicts.. However, they do not completely resolve human-wildlife conflicts since they do not always exclude destructive human impacts and also wildlife like lions, leopards, baboons etc cannot be retained in a protected area as they can cross the boundaries/demarcations set. Protected areas often only protect a part of an ecosystem or species range and 
wildlife dispersal from such areas may increase conflict with man. In Omay Zimbabwe, the failure to properly address the human wildlife conflicts in the effort to conserve wildlife and their habitat, whatever will be put in place to reduce the conflicts will lose stability and progress. The local communities will also lose the flavour for coexistence as conflicts will persist in this scenario.

Crop-raiding by wildlife in Omay Communal land occurs from November to April, with peaks from March to April, coinciding with the harvesting of maize mealies and sorghum/millet. This usually takes place during the night, that is, between late evenings to early mornings. This is also similar to wildlife killing or attacking livestock. Wildlife also attacks livestock in the afternoon if the livestock goes to the wildlife peripheries. Currently, Omay faces problems animals and most of which are the following wild animals, Baboons (Papio cynocephalus), Monkeys (Erythrocebus patas), Porcupine (hystrix Africae-austrialis), Leopard(Panthera pardus), Lions (Panthera leo), Crocodiles, African Elephant (Loxodonta Africana), Zebras (Equus burchelli), Warthogs (Phacochoerus aethiopicus), hippopotamuses (Hippopotamus amphibious), Buffalos (Syncerus caffer), Duiker (Sylvicapra grimmia), bushbucks (tragelaphus scriptus), Kudus (tragelaphus strepsiceros), squirrels, birds (both birds of prey and small birds that eat crops) ,and Impalas among others.

\section{The International Arena of Human Wildlife Conflicts}

Empirical literature reviews different papers that deal with wild-animals and humans coexisting and the conflicts they cause in different arenas and setups. These arenas includes in parks where park authorities are the custodians or outside the parks where wildlife is not allowed to roam around within and outside the confines of the wildlife habitats. Different countries have used different methods to deter wildlife intrusions and havoc they cause to human beings, crops and livestock. Different societies and conservation strategies have been set in place to abate the human-wildlife conflicts.

The literature of co-existing with wild-animals in unprotected areas is scant and inconclusive. As a result of paucity of accurate information on human-wildlife conflicts, most of the researchers studied problems that communities face without giving much attention to whether coexistence can be beneficial. Most of the studies have studied the protected areas where economic agents are the community members illegally accessing these protected and unprotected areas in search of firewood, medicine etc and getting affected by the wild animals. Muchapondwa, E., Carlsson, F., and Kohlin, G., (2005) assesses the economic value that the local communities living adjacent to national parks, game reserves and safari areas assign to wildlife, given that some people potentially consider it a public good while others consider it a public bad. In their analysis, they proposed that if the economic value of wildlife is large relative to alternative economic activities, then it would imply that wildlife conservation might be enhanced through devolution of wildlife user rights to the local communities.

Each year, thousands of people lose their lives and billions of dollars are lost in property because of human wildlife conflicts globally (Treves, A., 2007:1). Conventionally, people responded to wildlife threats by killing problem animals and eliminating wild habitat to prevent further losses. Nyhus, J. P., Osofsky, A, S., Ferraro, P., Madden, F., and Fischer, H., (2005) elicit that the risk of wildlife damage to crops, livestock and human lives provides incentives for the residents to kill wildlife and to reduce the quantity and quality of habitat on private and communal lands. Although this has been the case, there is always a group of people who continue to reap from the sales and troughs of the wild animals.

In order to resolve the wildlife problems, the concept of community based wildlife management (CBWM) has been introduced in most African countries (Mhlanga, L., 2001; Pantzare, M., and Vredin, M., 1993; Fischer, C., Muchapondwa, E., and Sterner, T., 2005). The argument is that, unless local communities are able to benefit financially from wildlife resources, conflicts between the two will continue infinitely. In NRDC, wild animals evade the places where humans stay destroying crops and threatening livestock and people. However, in cases where there are little incentives from coexisting with the wild-animals, communities may feel not compensated for their losses.

An important policy question is to know the intensity to which the local communities face due to the availability of wildlife in Omay communal lands. Studies by Bush, G., and Mwesigwa, R., (2008), looked at the benefits from protected area and found that it is the national and international communities that benefit more than the local communities. They found that the financial costs remained at the local level thus there was a strong argument to support improved public financing of the park from the national and international communities, but with the need to focus on addressing the inequity issues amongst those households most negatively impacted. NRDC in Zimbabwe offers an interesting case study of human wildlife conflicts for an unprotected area. Most of the research done so far on human-wildlife conflicts focused on protected areas.

Fischer, C., Muchapondwa, E., and Sterner, T., (2005) elicit that the establishment of national parks, game reserves and safari areas in the late 1920s that have since helped avert biodiversity and wildlife loss, but this has displaced rural communities from land that was traditionally theirs. Cultivation and grazing land was expropriated and the 
old practice of subsistence hunting became illegal. Local communities' hunters and other resource users were turned into poachers resulting in impoverishment, increasing malnourishment and an alienation from Western philosophies of conservation (DeGeorges, A. P., and Reilly, K. B., 2009). With this assertion, coexisting with wild-animals in NRDC will be a successful land-use option if the problems between humans and wildlife may be reduced to what can be acceptable to communities living adjacent to these marauding wildlife.

\section{Data Sources and Evaluation}

Data was collected in two phases. The first data was collected in December 2012 to test the questionnaire and only 50 questionnaires for 50 households were administered by the researcher. The final data collection was done on the 18th December 2013 to the 06th January 2014 with a total of 600 questionnaires for 600 households of which 482 questionnaires were completed without errors and were used in this study. The first round phase results were used to come up with the updated questionnaires that could meet the desired set objectives of the research. The enumerators were trained by the researcher and were divided to different perspective wards for data collection. The questionnaire was converted to local language by the trained enumerators during interviewing process. In total, the questionnaire took a minimum of an hour to complete and participation was voluntary. Households were selected randomly and there was no formula in choosing the households. Since the households were randomly selected throughout each community, each household had an equal chance to be chosen by virtue of the availability of the household head or relative to the household head. From the 600 questionnaires printed and administered, only 482 questionnaires were complete and had all the relevant information that pertains to the attaining of the research objectives. Data was collected in Omay communal land, Nyaminyami Rural District's 12 wards.

Table 1: Relationships to the household head

\begin{tabular}{|c|c|c|c|c|c|c|c|c|c|c|}
\hline Relationship to the household head & Household Head & Father & Mother/Wife & Brother & Sister & Uncle & Aunt & Son & Daughter & Nephew \\
\hline Percentages of interviewed & $45 \%$ & $4.6 \%$ & $13 \%$ & $5.4 \%$ & $5.2 \%$ & $3.3 \%$ & $5 \%$ & $8.3 \%$ & $6.2 \%$ & $3.7 \%$ \\
\hline
\end{tabular}

From table 1 above, the results shows that the household heads had a greatest percentage. $45 \%$ of the interviewed persons were the household heads. The least interviewed were the uncles to the household head with $3 \%$ of total households. This clearly shows that much of the data is represented by the household heads as they constitute the highest percentage contribution to this research.

Table 2: Respondents' Marital Status

\begin{tabular}{|c|c|c|c|c|c|}
\hline Marital status & Single & Married & Divorced & Widowed & Separated \\
\hline Percentage & $17.8 \%$ & $41.1 \%$ & $14.9 \%$ & $20.7 \%$ & $5.4 \%$ \\
\hline
\end{tabular}

The above table shows that the interviewed respondents had the highest percentages in married couples who topped $41 \%$ and the least is $5.4 \%$ of those who are separated. Anecdotal evidence says most of the widowed were mainly due to the prevalence of HIVIAIDS pandemic although this research could not focus much in addressing on this issue.

Table 3: Gender wise relationships

\begin{tabular}{|l|c|c|}
\hline Gender of respondent & Male & Female \\
\hline Percentage of respondents & $56.8 \%$ & $43.2 \%$ \\
\hline
\end{tabular}

Of the interviewed respondents, $57 \%$ were male and $43 \%$ were female. Looking at the demographics of Omay Communal Land, the greater population is men than women. This shows that much of the data evaluated is represented by male counterparts than the females.

Table 4: Age of the respondents

\begin{tabular}{|l|c|c|c|c|}
\hline Age of respondents & Less than 17 years & $18-32$ years & $33-65$ years & $65+$ years \\
\hline Percentages of respondents & $3.1 \%$ & $44 \%$ & $40.5 \%$ & $12.4 \%$ \\
\hline
\end{tabular}


Most of the respondents fall in the category of 18 to 32 years with 44\%. This shows the active populations and most of them are at high schools, further learning colleges and some involved in income generating activities. This age group shows the youths who still have the energy to do greater exploits in small business, income generating projects or further learning. The second age group is 33-65 years and is composed of the population that is nearer to retiring age of 65 years and some who have just completed high school, some having university degrees and at work. This shows the working age and most of them have something they can point to be their permanent work or source of survival work. The least interviewed were people with less than 17 years and they only contributed $3 \%$ of all the respondents. These are students who just finished primary school and some are enrolled at secondary schools. The second category is represented by the 65 years and above and represents the retired and old age groups. This is composed of $12 \%$ of all the interviewed households population interviewed.

\section{Reports on wildlife}

Table 5: Crop and livestock damage reports data

\begin{tabular}{|c|c|c|c|c|c|c|c|c|c|c|c|c|}
\hline & 2001 & 2002 & 2003 & 2004 & 2005 & 2006 & 2007 & 2008 & 2009 & 2010 & 2011 & 2012 \\
\hline Elephant & 869 & 1289 & 1112 & 450 & 114 & 846 & 569 & 438 & 665 & 756 & 823 & 924 \\
\hline Buffalo & 17 & 41 & 12 & 0 & 4 & 23 & 3 & 5 & 35 & 40 & 51 & 67 \\
\hline Hyena & 2 & 1 & 3 & 0 & 4 & 1 & 0 & 0 & 0 & 0 & 2 & 3 \\
\hline Lion & 17 & 13 & 25 & 2 & 7 & 7 & 3 & 6 & 4 & 8 & 9 & 12 \\
\hline Hippo & 2 & 2 & 0 & 1 & 2 & 16 & 25 & 28 & 2 & 16 & 27 & 34 \\
\hline Crocodile & 2 & 1 & 4 & 0 & 14 & 7 & 10 & 31 & 37 & 32 & 41 & 51 \\
\hline Leopard & 0 & 3 & 1 & 0 & 0 & 2 & 0 & 0 & 0 & 1 & 0 & 2 \\
\hline
\end{tabular}

\section{Source: NRDC data}

The figure above shows the reports that were made for crop and livestock damage. It shows that elephants are the mere cause of the conflicts in NRDC as indicated by the highest reports made from 2001 to 2012. The year 2002 has the highest reports and it topped 1289 reports. The second group in crop and livestock damage was buffaloes and 67 reports were made to the NRDC in year 2012 showing the highest reports ever made since 2001 . The crocodiles were the third and lions the forth groups of wildlife that has been reported for damaging crops and consumption of wildlife. The hippopotamuses, leopards and hyenas had the least reports made to NRDC for wildlife conflicts in affecting crops and livestock.

Table 6: Reported livestock killed by wildlife from year 2003 to 2012

\begin{tabular}{|c|c|c|c|c|c|}
\hline & Livestock killed & Lion & Leopard & Crocodile & Hyena \\
\hline \multirow{3}{*}{2003} & Goats & 29 & 2 & 0 & 0 \\
\hline & Donkey & 19 & 0 & 0 & 0 \\
\hline & Cattle & 5 & 0 & 0 & 0 \\
\hline \multirow{3}{*}{2004} & Goats & 61 & 7 & 0 & 0 \\
\hline & Donkey & 5 & 0 & 0 & 0 \\
\hline & Cattle & 5 & 0 & 0 & 0 \\
\hline \multirow{3}{*}{2005} & Goats & 2 & 7 & 37 & 4 \\
\hline & Donkey & 7 & 0 & 4 & 0 \\
\hline & Cattle & 4 & 0 & 0 & 0 \\
\hline \multirow{3}{*}{2006} & Goats & 9 & 3 & 15 & 0 \\
\hline & Donkey & 3 & 1 & 0 & 0 \\
\hline & Cattle & 2 & 0 & 0 & 0 \\
\hline \multirow{3}{*}{2007} & Goats & 4 & 2 & 0 & 0 \\
\hline & Donkey & 10 & 1 & 2 & 0 \\
\hline & Cattle & 3 & 0 & 0 & 0 \\
\hline \multirow{3}{*}{2008} & Goats & 42 & 3 & 6 & 11 \\
\hline & Donkey & 4 & 0 & 0 & 0 \\
\hline & Cattle & 6 & 0 & 0 & 0 \\
\hline
\end{tabular}




\begin{tabular}{|c|c|c|c|c|c|}
\hline \multirow{3}{*}{2009} & Goats & 19 & 2 & 12 & 3 \\
\hline & Donkey & 16 & 0 & 1 & 0 \\
\hline & Cattle & 4 & 0 & 0 & 0 \\
\hline \multirow{3}{*}{2010} & Goats & 34 & 4 & 32 & 5 \\
\hline & Donkey & 15 & 1 & 2 & 0 \\
\hline & Cattle & 2 & 0 & 0 & 0 \\
\hline \multirow{3}{*}{2011} & Goats & 31 & 2 & 8 & 3 \\
\hline & Donkey & 10 & 3 & 3 & 0 \\
\hline & Cattle & 6 & 0 & 0 & 0 \\
\hline \multirow{3}{*}{2012} & Goats & 19 & 11 & 32 & 3 \\
\hline & Donkey & 9 & 3 & 2 & 0 \\
\hline & Cattle & 7 & 0 & 0 & 0 \\
\hline
\end{tabular}

\section{Source: NRDC data}

The above figure shows that goats are victims as evidenced by the highest numbers of reported kills. These are followed by donkeys with the second highest. Donkeys are used for draught power in NRDC and most of these donkeys are the source of crops incomes as they are used in pulling ploughs during weeding. Cattle hold the greatest values in times when communities sell them locally and they are used for draught power as well as paying lobola.

Table 7: Number of people killed by wildlife from 1992 to 2013 in NRDC

\begin{tabular}{|c|c|}
\hline Year & No. of pple killed by wildlife \\
\hline 1992 & 1 \\
\hline 1993 & 0 \\
\hline 1994 & 1 \\
\hline 1995 & 2 \\
\hline 1996 & 2 \\
\hline 1997 & 3 \\
\hline 1998 & 4 \\
\hline 1999 & 0 \\
\hline 2000 & 8 \\
\hline 2001 & 11 \\
\hline 2002 & 7 \\
\hline 2003 & 3 \\
\hline 2004 & 8 \\
\hline 2005 & 1 \\
\hline 2006 & 1 \\
\hline 2007 & 1 \\
\hline 2008 & 4 \\
\hline 2009 & 4 \\
\hline 2010 & 2 \\
\hline 2011 & 8 \\
\hline 2012 & 0 \\
\hline 2013 & 5 \\
\hline
\end{tabular}

\section{Source: NRDC data}

The above figures show that wild animals are a threat to human lives. The people who lost their lives from in the past two decades have totaled to 76 human beings. These have been reported and there might be others who may have lost their lives and they were not reported to the NRDC. This is a great number to lose to wildlife.

\section{NRDC's Measures to Reduce Human-Wildlife Conflicts}

The NRDC have compensated some households that have had their relatives killed with wildlife. The amounts which are not disclosed to the communities involve the assistance in the form of burial/funeral expenses. The NRDC also provides 
meat at these funerals for the mourners and the relatives at the funeral. There is no cash that the NRDC disburse to these communities to help them to pay for death due to wildlife conflicts. In the case of crop losses, the villagers and the communities facing these challenges must report to NRDC who then inspects and chase the wildlife towards their habitats by using fire arms. In NRDC there is no party or organization that is available o compensate communities for their crop, livestock or human deaths due to the availability of wildlife in the unprotected areas of Omay Communal Lands. A demarcation of wildlife areas and residential areas is there but people are still encroaching for reasons that include collection of firewood, cutting down trees for farming, gathering fruits, poles and also building houses for inhabiting purposes.

Currently there are two measures that are in place to avoid people to intermingle with wildlife. These two includes the use of conservancies and problem animals awareness. At present there is one conservancy called Mackenzie Game Conservancy, some of which are proposals to be established later in the future. The conservancy proposals include the Manyuli Conservancy and Tiger Bay Conservancy.

The NRDC is expecting the conflicts between the wildlife and humans to reduce in the next two decades due to the fact that the animals are now decreasing in population and some large problem animals are killed in the event that they injure or kill a human being. Most often the NRDC does not take much time to attend to the reports of conflicts between wildlife and humans. The moment the person reports, then the NRDC attends to it unless limited by fuel, transport and lack of rifles for use at the moment of the report.

If the NRDC catches the person poaching wildlife, they arrest the person(s) and send the person(s) to the police. All the wildlife that kills/injure a human being is eliminated and the meat given to the local communities and the other portion to the funeral given the animal can be eaten. Due to wildlife and humans conflicts, NRDC recorded 3 buffaloes, 4 hippopotamuses and 26 elephants that were killed in 2009; in 201010 elephants, 2 hippopotamuses were killed and finally records in 2011 only recorded 11 elephants killed due to human-wildlife conflicts (Source: NRDC data). There is no wildlife that is killed just to give meat to benefit the local communities living adjacent to the wildlife in a year except for the meat that the communities gets from tourists who kill wildlife they buy and provide it to the locals for free.

If an option can be given to relocate the wildlife in Omay Communal Lands, the NRDC proposes a cost of US\$2 000000 which can be paid in the form of a loan for 20 years. This will totally reduce and eradicate human-wildlife conflicts.

\section{Conclusion}

Human wildlife conflicts have been there since the creation of Adam, the first man on earth. The bible elicit that wildlife was created first before human beings. The snake spoke to a person to eat the forbidden fruit and from there God cursed the humans and wildlife allowing them to be enemies for life. In this research, it can be concluded that the programmes that have been set on in Omay Communal Land, Nyaminyami Rural District Council are not a total solution to the problem, rather they try to alleviate human wildlife conflicts to a lower level. Wildlife cannot detect jurisdictional boundaries between where they should be confined and where humans can occupy. In Omay communal land there is currently no programme that is there to restore the animals that stays in human dominated areas to put them to where they should belong in the land conserved for them. In NRDC, buffaloes may stay near humans' periphery for a week until they feel they are not safe and they return to the hiding places. Therefore there is a need to involve the communities, the different government agencies and even non-governmental organizations to deal with the issue of coexistence of wildlife and human in Omay communal land. Therefore the cooperation and collaboration of these parties/stakeholders may help alleviate human wildlife conflicts in Omay Communal Land, NRDC in Kariba.

Omay communal lands, NRDC offers an interesting case study for wildlife coexistence with the local communities. The locals have been staying together with the wild animals exercising their primitive rights through slaughtering wildlife for meat, hunting for the pot, killing wildlife to get hides for traditional attires and sense of pride and honour especially when a lion is killed. These are the benefits that NRDC residents are gaining from wildlife coexistence but they are silent benefits as these benefits cannot be quantified in monetary terms. Communities view wildlife on a daily basis for no price. These are benefits among valuable benefits in which NRDC communities yield from the presents of wildlife. The absence of market for these wildlife resources negatively affects the well-being of human beings by reducing the benefits that can be generated from wildlife resources. This gives a room for more research for NRDC wildlife conflicts to look deep into the economic valuation of coexistence of humans and wildlife in NRDC (Jeke L, forthcoming). An economic valuation method can be used to calculate the price and economic values attached to wildlife resources in Omay Communal lands. 


\section{Recommendations}

Currently there are some conservancies that the NRDC have put in place. As could be derived from this research, conservancies are not a panacea as conflicts between the humans and wildlife still persists in NRDC. Communities of people who maintain positive attitudes will be those where conservation efforts have the greatest chance of being successful. The perceptions of the communities towards wildlife are essential in Omay Communal lands, NRDC as these forms the bases of which they can coexist without negative attitudes. The benefits that the communities have been receiving from the NRDC as benefits from coexisting with wildlife should be acknowledged as payments to the trouble and trauma they face from the presents of the wildlife. If the communities could accept that they are earning something from coexistence with wildlife, they are more likely to accept livestock and crop damage caused by these wild animals. The NRDC should invest much in educating the communities for coexistence to be tolerated by the communities living with the wildlife in Omay Communal Lands. NRDC has to put stringent rules and regulations for the communities to avoid encroachment into wildlife habitats. The increasing rate of human population growth has expanded the human interface into wildlife areas due to search of dwelling places that they call homes and conversion of natural lands that habitat wildlife into agricultural lands.

\section{Limitation of the Study and Areas of Further Research}

A mere analysis of the coexistence between humans and wildlife is not enough. I believe a contingent valuation method will give a view on how prepared are the locals willing to coexist with wildlife. This will also show how much they value their wildlife despite the challenges and problems they face due to their availability. The author is working on the CVM method in the coexistence with wildlife in NRDC and this will provide how ready the communities are to coexist with the marauding wildlife.

\section{Acknowledgments}

This analysis was funded by the University of Fort Hare Govan Mbeki Research and Development Centre (GMRDC).

Special thanks to Govan Mbeki Research Development Centre (GMRDC) for financing data collection for this research

\section{References}

Anderson, J., Bakker, L., Lagrange, M., Lamarque, F., Fergusson, R., and Osei-Owusu, F. A. O., (2009). Human-wildlife conflict in Africa. Causes, consequences and management strategies. FAO, 2009. 110 pp. ISBN 9789251063279

Anderson, L. T., (2004). Markets and the environment: Friends or foes? Nord Family Foundation, the Property and Environment Research Center, and the Center for Business Law and Regulation

Balint, J. P., and Mashinya, J., (2008). CAMPFIRE through the Lens of the 'Commons' Literature: Nyaminyami Rural District in Post2000 Zimbabwe. Journal of Southern African Studies, forthcoming (January 2008)

Barnes, I. J., MacGregor, J., and Weaver, L. C., (2001). Economic analysis of community wildlife use initiatives in Namibia. DEA research discussion paper, No 42, August 2001

Bush, G., and Mwesigwa, R., (2008). Costs and benefits from protected areas action research project Bwindi impenetrable forest national park, Uganda. Unknown publisher

Conyers, D., (2002). Whose elephants are they? Decentralization of control over wildlife management through the campfire program in Binga district, Zimbabwe. Environmental governance in Africa. Working papers: wp \#4

DeGeorges, A. P., and Reilly, K. B., (2009). The realities of Community Based Natural Resource Management and biodiversity conservation in Sub-Saharan Africa. Sustainability 2009, 1, 734-788; doi:10.3390/su1030734

Distefano E, (2005). Human-Wildlife Conflict worldwide: collection of case studies, analysis of management strategies and good practices. http://www.fao.org/SARD/common/ecg/1357/en/HWC_final.pdf

Duff R, (2000). Killing for conservation: wildlife policy in Zimbabwe. James Currey Publishers. ISBN 123450403020100

Emerson, C. (2000). Natural Resources Management and Sustainable Livelihoods: Compatibility or Conflict. A summary of processes and evidence with three supplementary briefing sheets. London: DFID

Emerton, L., (2000). The nature of benefits and the benefits of nature: Why wildlife conservation has not economically benefitted communities in Africa. Community conservation research in Africa: Principles and comparative practice. Paper No. 5

Field, B. C., (1997). Environmental economics: An introduction. The McGraw-Hill Companies, Inc., New York

Fischer, C., Muchapondwa, E., and Sterner, T., (2011). A bio-economic model of community incentives for wildlife management under CAMPFIRE. Environmental and Resource Economics, 48 (2), 303-319 
Fischer, C., Muchapondwa, E., and Sterner.T., (2009). Bioeconomic model of community incentives for wildlife management before and after CAMPFIRE. Working papers in Economics, No 410

Fischer, C., Muchapondwa, E., and Sterner.T., (2005). Bioeconomic model of community incentives for wildlife management before and after CAMPFIRE. Discussion Paper 05-06

Fox, G., (2007). The real Coase theorems. Cato Journal, Vol. 27, No. 3 (Fall 2007)

Gardner, R., Herr, A., Walker, J. A., and Ostrom, E., (1998). The power and limitations of proportional cutbacks in common-pool resources. October 13, 1998

Hasler, R., (1999). An overview of the social, ecological and economic achievements and challenges of Zimbabwe's CAMPFIRE programme. Evaluating Eden series. International Institute for Environment and Development (IIED): London, UK, 1999. Discussion Paper No 3.

Hill, M. C., (2004). Farmers' perspectives of conflict at the wildlife-agriculture boundary: Some lessons learned from African subsistence farmers. Human Dimensions of Wildlife, 9:279-286, 2004

Hoare, R.E., (1999). Determinants of human-elephant conflict in a land-use mosaic. Journal of Applied Ecology 36: 689-700.

Hopkins, J., Scherr, S., and Gruhn, P., (1994). Food security and the commons: Evidence from Niger. Washington, D.C.: International Food Policy Research Institute. Mimeo http://campfirezimbabwe.org. Accessed 31 August 2012 http://www.paceproject.net/ Userfiles/File/Living\%20With\%20Wildlife/Human\%20wildlife\%20conflict.pdf

Jodha, S. N., (1992). Common property resources: A missing dimension of development strategies. World Bank Discussion Paper No. 169. Washington, D.C.: World Bank

Jones, B., and Weaver, C., (2007). CBNRM in Namibia: Growth, trends, lessons and constraints.

Jones, B. T. B., and Barnes, I. J., (2006). Human wildlife conflict study. Namibian case study. Final report October 1, 2006

King, M. D., and Mazzotta, M., (2003). Contingent evaluation method. [Online]. Available : http//www.uri.edu/cels/enre/mm.htm. [accessed 13 July 2012]

Magome, H., (2007). Interactions between elephants and people. Conservation and Society (2007)

Martinez-Espineira, R., (2004). A Box-Cox double-hurdle model of wildlife valuation: the citizen's perspective. Department of Economics, St. Francis Xavier University. June 2004

Mashinya, J., (2007). Participation and devolution in Zimbabwe's CAMPFIRE program: Findings from local projects in Mahenye and Nyaminyami. Faculty of the Graduate School of the University of Maryland, College Park

Messmer, A. T, (2009). Human-wildlife conflicts: emerging challenges and opportunities. Human-Wildlife Conflicts 3(1):10-17, Spring 2009

Mhlanga, L., (2001). Conflict between wildlife and people in Kariba town, Zimbabwe. University Lake Kariba Research Station, University of Zimbabwe. Zambezia (2001), XXVIII (i)

Mombeshora, S., and Le Bel, S., (2010). Community based game ranching and politics in Chiriwo Ward of Mbire district, Zimbabwe. ISDA 2010, Montpellier, June 28-30, 2010

Muchapondwa, E., Carlsson, F., and Kohlin, G., (2005). Can local communities in Zimbabwe be trusted with wildlife management? : Evidence from contingent valuation of elephants. JEL Classification: C25, H41, Q26

Muchapondwa, E., (2003). The economics of community-based wildlife conservation in Zimbabwe. Economic studies, Department of economics, School of economics and commercial law, Goteborg University

Murphree, M., (2004). Communal approaches to natural resource management in Africa: From whence and to where? Journal of International Wildlife Law and Policy, 7, 3-4 (2004), p. 204

Murphree, W. M., and Mazambani, D., (2002). Policy Implications of Common Pool Resource Knowledge: A Background Paper on Zimbabwe. UK Department for International Development under its Natural Resources Systems Programme Semi-Arid Production System (Project R7973). http://www-cpr.geog.cam.ac.uk

Muruthi, P., (2005). Human wildlife conflict: Lessons learned from AWF's African heartlands. AWF Working Papers. July 2005

Musona, M., (2011). An exploration of the causes of social unrest in Omay communal lands of Nyaminyami district of Zimbabwe: A human needs perspective. Department of academic administration, Examination section, Summerstarnd Nelson Mandela metropolitan university, Port Elizabeth

Nyaminyami Nutrition Survey, (2002). Nutrition Survey, Nyaminyami District, (Kariba Rural) Mashonaland West Province, Zimbabwe. Save the Children in collaboration with the Nyaminyami Food and Nutrition Management Team. July, 2002

Nyhus, J. P., Osofsky, A, S., Ferraro, P., Madden, F., and Fischer, H., (2005). Bearing the costs of human-wildlife conflict: The challenges of compensation schemes. Cambridge University Press, Cambridge (2005)

Osborn, V. F., and Parker, E.G., (2003). Towards an integrated approach for reducing the conflict between elephants and people: a review of current research. Oryx Vol 37 No 1 January 2003

Osborn, V. F., and Anstey, S., (2002). Elephant/human conflict and community development around the Niassa Reserve, Mozambique. Consultancy for WWF/SARPO. April 2002

Parker, E. G., Osborn, V. F., Hoare, E. R., and Niskanen, S. L., (2007). A training course for community-based approaches in Africa. Participant's manual, March 2007

Pantzare, M., and Vredin, M., (1993). The campfire programme in Nyaminyami: A study of the local population's incentives to support the programme. Umea Business School, Department of Economics

Parker, E. G., and Osborn, V. F., (2006). Investigating the potential for chilli Capsicum annuum to reduce human-wildlife conflict in Zimbabwe. Oryx Vol 40 No 3 July 2006 
Schulz, C. E., and Skonhoft, A., (1996). Wildlife management, land-use and conflicts. Environment and Development Economics, 1, 265280

Scudder, T., (2005). The Kariba case study. Social science working paper 1227, June 2005

Seidl, I., and Tisdell, A. C., (1999). Analysis. Carrying capacity reconsidered: from Malthus' population theory to cultural carrying capacity. Ecological economics 31 (1999) 395-408

Shemwetta, D. T. K., and Kideghesho, J. R., (2000). Human-wildlife conflicts in Tanzania: What research and extension could offer to conflict resolution. Human-Wildlife conflicts in Tanzania. Proceedings of the 1 st University Wide Conference, $5 \mathrm{t} \mathrm{h}-7$ th April 2000: Volume 3

Skonhoft, A., (1998). Resource utilisation, property rights and welfare-wildlife and the local people. Ecological Economics 26: 67-80

Skonhoft, A., (2005). The costs and benefits of animal predation: An analysis of Scandinavian wolf re-colonization. Ecological Economics. 58 (2006) 830- 841

Skonhoft, A., and Schulz, E. C., (2005). On the Economics of ecological nuisance. Working Paper Series in Economics and Management, No. 02/05, March 2005

Skonhoft, A., and Schulz, E. C., (2003). On the Economics of ecological nuisance. Working Paper Series in Economics and Management, April 302003

Skonhoft, A., and Solstad, J. T., (1998). The political economy of wildlife exploitation. Land Economics, 74, 16-31

Skonhoft, A., and Solstad, J. T., (1996). Wildlife management, illegal hunting and conflicts. A bioeconomic analysis. Environment and Development Economics, 1, 165-181

Stevens, H. T., Echeverria, J., Glass, J. R., Hager, T., and More, A. T., (1991). Measuring the existence value of wildlife: What do CVM estimates really show? Land Economics, Vol. 67, No. 4 (Nov., 1991), pp. 390-400

Taylor, M., (2006). CBNRM and pastoral development in Botswana: Implications for San land rights. Oxford University African Studies Centre and African Environments Programme. Presentation paper, December 2006.

Taylor, R.D., (1982). Buffer zones: Resolving conflict between human and wildlife interests in the Sebungwe region. Zimbabwe Agricultural Journal 79, 179-184

Tietenberg, T., and Lewis, L., (2010). Environmental economics and policy. Sixth edition. Publisher- Denice Clinton. Pearson education Inc

Tietenberg, T., (2000). Environmental and natural resource economics. New York, Addisson Wesley

Treves, A., (2007). Balancing the needs of people and wildlife: When Wildlife Damage Crops and Prey on Livestock. Tenure brief; No. 7 , 2007 